* Doutorando em Estudos Estratégicos Internacionais (UFRGS), Mestre em Direito (UNISINOS), Professor de Direito Internacional (ESADE), Assessor Jurídico do Estado do Rio Grande do Sul. E-mail: lvazferreira@gmail.com

** Mestrando em Direito (UFRGS), Especialista em Direito Empresarial (UFRGS), MBA em Direito da Economia e da Empresa (FGV), Advogado. E-mail: mlucietto@terra. com.br

\section{A cooperação transgovernamental financeira na regulação do mercado de capitais}

\section{TransgOVERNMENTAL FINANCIAL COOPERATION IN THE REGULATION OF CAPITAL MARKET}

\author{
Luciano Vaz Ferreira * \\ Marcelo Leão Lucietto **
}

Resumo: O objetivo do artigo é estudar a regulação transnacional de questões financeiras, especialmente no que diz respeito ao mercado de capitais. De modo a conferir maior efetividade às práticas estatais regulatórias, propõem-se a utilização de um novo paradigma teórico, o transgovernamentalismo. A adoção dessa teoria permite uma verdadeira revolução no campo da cooperação internacional financeira, tornando a comunicação entre entidades regulatórias mais técnica e eficiente.

Palavras-chave: Cooperação Internacional. Transgovernamentalismo. Mercado de Capitais.

Abstract: The aim of this paper is to study the transnational regulation of financial issues, especially with regard to the capital market. In order to give greater effect to state regulatory practices, we propose the use of a new theoretical paradigm, transgovernmentalism. The adoption of this theory allows for a true revolution in the field of international financial cooperation, making communication between regulatory bodies more technical and efficient.

Keywords: International Cooperation. Transgovernmentalism. Capital Market. 


\section{INTRODUÇÃO}

A globalização operou profundas transformações sociais nas últimas décadas. No campo econômico, empreendeu-se uma verdadeira revolução. A ascensão do capitalismo como modelo dominante promoveu a integração e interdependência dos mercados nacionais, permitindo a rápida movimentação de capital além das fronteiras políticas.

No cenário de economia global, grandes somas de dinheiro migram de um país ao outro no menor sinal de incerteza, sempre buscando um mercado mais seguro e rentável. O capital investidor deixa de ser dotado de um perfil empreendedor, marcado por grandes investimentos voltados a projetos, como os de construção de infra-estrutura, e passa a ter perfil financeiro, ligado a operações junto ao mercado de capitais, dependente da valorização do preço dos papeis em bolsas de negociação. O resultado disso é uma mudança do risco da atividade para o risco financeiro.

O Brasil, nesse contexto, ocupa posição privilegiada, que se reflete tanto no crescimento econômico quanto na condição de mercado vulnerável. A globalização permitiu a ascensão de mercados que tradicionalmente não possuíam grande expressão, como é o caso dos "BRICS", que, ante as altas taxas de desenvolvimento e, principalmente, pelo potencial de manutenção destas taxas pelos próximos anos, assumiram a condição de grandes destinatários de capital investidor no mundo.

O presente trabalho tem como objetivo analisar algumas formas de atividade regulatória do Estado no mercado financeiro, especialmente no mercado de capitais, frente às mudanças no cenário internacional. $\mathrm{O}$ artigo é divido em quatro partes. Primeiramente, é feito um panorama da regulação no âmbito interno. Após, discorre-se sobre a possibilidade de aplicação da tese do transgovernamentalismo à cooperação financeira. Ao final, parte-se para uma análise da função dos memorandos de entendimento, novo instrumento jurídico, encerrando-se com o estudo do papel das organizações internacionais atuantes no setor.

\section{A REGULAÇÃO ECONÔMICA SOB O PONTO DE VISTA INTERNO}

Sem adentrar em grandes debates de modelos teóricos econômicos e ideológicos, entende-se que o Estado exerce o importante papel de regulador 
da economia, seja para garantir, em intervenção mínima, a liberdade econômica ou, de maneira mais intensa, corrigir as discrepâncias do mercado.

A regulação econômica encontra esteio em três objetivos principais: manter a competição no mercado, limitando o uso do poder de monopólio das empresas; proteger os consumidores no caso de existência de assimetrias informacionais que possam levar a abusos; e lidar com situações de externalidades negativas em que os custos sociais de falhas de mercado ou da falência de suas empresas excedam os custos privados (LOYOLA, 2010, p.64).

A forma de manifestação da regulação econômica está estritamente ligada ao modelo de Estado adotado. O paradigma estatal tradicionalmente difundido no Brasil é marcado por uma intensa participação do Estado na economia, grande centralização de poder e hierarquização da administração pública. Observa-se, ainda, um elevado grau de influência política em detrimento da gestão técnica, conduzindo-se à morosidade e a ineficiência da máquina estatal, incapaz de cumprir os anseios sociais (BINENBOJM, 2007, p.1). Nesse contexto, o mercado financeiro é visto como um mero instrumento para atender às necessidades de financiamento das atividades empresariais (YAZBEK, 2009, p.46).

Grandes transformações enfrentadas pela sociedade no decorrer do Século XX forçaram a redefinição do paradigma estatal. Com a globalização, o capitalismo expandiu-se sem freios, integrando economicamente quase todas as nações. O fluxo da capital, por sua vez, passa a ser internacionalizado, descolando-se dos subsistemas econômicos nacionais (IANNI, 2004, p.68). Nesse novo sistema econômico, destacam-se a expansão do investimento estrangeiro e a proliferação de empresas multinacionais, estabelecendo-se uma economia sem fronteiras (ARNAUD, 1999, p.01).

Aliado a isso, operacionalizou-se uma verdade revolução tecnológica, especialmente nos meios de comunicação. A evolução do sistema de transportes e a interconectividade propiciada pela internet facilitou o acesso à informação e aproximou as pessoas (COMISSÃO SOBRE GOVERNANÇA GLOBAL, 1996, p.07).

Cria-se, assim, um o fluxo internacional de capitais, pessoas, bens e serviços (ARNAUD, 1999, p.02). Como resultado, os Estados, antes poderosos, tornaram-se figuras impotentes em lidar com a nova dinâmica globalizante. Pode-se dizer que no mundo atual grande parte das interações globais ocorre sem intervenção estatal (KEOHANE e NYE, 1971, p.332). 
Para concretizar os mecanismos regulatórios de cunho econômico, indispensáveis para uma economia ainda em desenvolvimento, como é o caso da brasileira, era necessário superar a imobilização estatal frente à independência e a internacionalização dos mercados. Promoveu-se, assim, uma reforma administrativa.

A mudança deu-se com o surgimento de agências reguladoras, que consistem em um corpo técnico voltado para atuação em determinado setor da economia, de forma independente às questões políticas, ideológicas e partidárias. São frutos da necessidade enfrentada pelo Estado de acompanhar a especialização e a fragmentação da sociedade, de modo a conferir maior eficiência no enfrentamento dos novos problemas sociais.

Nas palavras de Aragão, o processo fragmentário da administração pública permitiu a criação de órgãos e entidades independentes, dotadas de autonomia e descentralização material, capazes de ponderar diversos interesses sociais. A instituição dessas agências visa "assegurar a não imposição de regulações de cunho eminentemente político, às vezes mesmo de cunho políticoeleitoral e, desta forma, desnecessárias ou desvirtuadas para os fins públicos aos quais a regulação estatal visa a atender" (ARAGÃO, 2003, p.201).

Observa-se, assim, que a diminuição da participação direta do Estado na economia foi compensada pela regulação econômica feita por agências reguladoras, mais especializadas tecnicamente, garantindo-se o cumprimento da função social estatal.

No que diz respeito à regulação do mercado financeiro, pode-se dividi-la em quatro grandes segmentos: o mercado bancário, no Brasil submetido à regulação pelo Banco Central do Brasil (BACEN); o mercado de capitais, adstrito à fiscalização pela Comissão de Valores Mobiliários (CVM); o mercado securitário, regulado pela Superintendência de Seguros Privados (SUSEP); e o mercado previdenciário, vinculado à fiscalização pela Secretaria de Previdência Complementar (SPC).

Devido à complexidade do assunto, será dada maior atenção à regulação do mercado de capitais no Brasil, exercida pela CVM. Cumpre referir que, inicialmente, tratava-se apenas de uma diretoria do Banco Central do Brasil, intitulada Diretoria de Mercado de Capitais. Em 1976, com a Lei $n^{0}$. 6.385, foi transformada em uma instituição governamental autônoma destinada exclusivamente à regulamentar, fiscalizar e desenvolver o mercado de capitais.

Suas funções encontram-se previstas no artigo $4^{\circ}$ dessa lei: estimular a formação de poupança e sua aplicação em valores mobiliários; promover a 
expansão e o funcionamento eficiente e regular do mercado de ações; proteger os titulares de valores mobiliários e os investidores do mercado; evitar ou coibir modalidades de fraude ou manipulação e, por fim, assegurar o acesso público a informações sobre os valores mobiliários negociados e sobre as companhias que os tenham emitido.

A CVM é dotada de poderes normativos e punitivos para o eficiente desempenho de suas funções. Além das atribuições tipicamente regulatórias, a CVM tenta assumir a condição de fórum de debates com os demais integrantes do sistema. Nesse passo, audiências públicas para discussão e aprimoramento das minutas elaboradas para regulação de novos temas ou para a atualização das normas já editadas são comumente realizadas pelo órgão regulador.

Atualmente, a CVM estimula os mecanismos de auto-regulação, que consistem na atribuição de funções regulatórias a agentes privados (entidades ou empresas) de determinado setor. Essa delegação fundamenta-se na redução dos custos de atuação do órgão estatal; na aproximação da autoridade autoreguladora dos agentes, conferindo-lhe agilidade e sensibilidade; na aceitação pelos agentes de normas criadas pela própria comunidade, reduzindo a necessidade de intervenção do órgão regulador.

Delineado o panorama regulatório do mercado de capitais no contexto brasileiro, passa-se a abordar as transformações enfrentadas na forma de atuação do Estado, a fim de melhor atender aos novos problemas que surgiram em virtude dos processos econômicos e sociais, conferindo, a partir de então, maior ênfase ao cenário internacional.

\section{TRANSGOVERNAMENTALISMO COMO MODELO PARAA COOPERAÇÃO REGULATÓRIA}

No plano internacional, tem-se uma ordem na qual o Estado é visto, tradicionalmente, sob o véu da soberania, como uma estrutura única. Impera a rígida divisão entre "assuntos internos", impenetráveis a qualquer interferência estrangeira e a "política externa”, responsável pelo estabelecimento de relações de amizade e inimizade entre os Estados, que negociam em pé de igualdade. As comunicações entre as estruturas estatais são, por sua vez, feitas pelo chefe de Estado, com auxílio do Ministério das Relações Exteriores, verdadeiros guardiões da soberania (SLAUGHTER, 2004, p.12).

A globalização e o desenvolvimento de relações transnacionais fizeram com que as sociedades ficassem mais sensíveis às perturbações externas. Com 
uma nova dinâmica de comunicação instaurada, questões como crises financeiras, atividades da criminalidade organizada, pandemias, imigração ilegais, entre outros, não respeitam os limites territoriais da autoridade estatal. Sendo assim, os governos se viram obrigados a projetar suas próprias políticas públicas internas pensando no comportamento de outros países. Como resultado, tem-se a necessidade de uma coordenação de ações, estabelecendo-se, assim, contatos entre os governos (KEOHANE e NYE, 1974, p.41-42).

Nesse contexto, observa-se que não há mais espaço para um modelo de política externa centralizador na figura do chefe de Estado ou ministro das relações exteriores. Criam-se canais diretos de comunicação, formais ou informais, entre departamentos especializados de governo de diferentes países. Estes irão contatar suas contrapartes estrangeiras com o objetivo de solucionar os problemas transnacionais (KEOHANE e NYE, 1974, p.43).

Isso irá ocasionar uma mudança na estrutura estatal, tanto no plano interno como externo. Observa-se uma desagregação do Estado em partes funcionais distintas, dotadas de caráter técnico e relativa autonomia em relação ao poder central (aponta-se o caso das agências reguladoras). Essas estruturas manterão contato com suas contrapartes estrangeiras, criando uma densa rede de relações de ordem "transgovernamental", conforme a concepção de Anne-Marie Slaughter (1997, p.184).

Keohane e Nye definem esse novo modo de diplomacia como o "conjunto de interações diretas entre subunidades de diferentes governos que não são controladas pelas políticas dos órgãos centrais responsáveis pela política externa, como o chefe do executivo e corpo diplomático" (1971, p.335).

No plano econômico, é evidente que o Estado em sua concepção clássica apresenta-se incapaz de lidar sozinho com fluxos econômicos independentes e internacionalizados (IANNI, 2004, p.68). Para Aragão, é preciso a construção de mecanismos globais de regulação de um mercado de características também globais, com o objetivo de prevenir as injustiças causadas diante da ausência de normas tipicamente internacionais (2003, p.201). Sendo assim, torna-se necessário uma regulação transgovernamental do mercado financeiro, visto que dado a dimensão extraterritorial do assunto, não há como um regulador realizar o seu trabalho sem que uns cooperem com os outros.

A própria vulnerabilidade da economia internacional serve como argumento para a criação dos referidos laços transnacionais. Não se pode olvidar da emergência das crises financeiras, especialmente aquelas que abateram sistematicamente a economia mundial nos últimos anos (BRUNER e CARR, 
2007, p.01). Conforme Loyola, "a intensidade e a virulência da crise deflagrada pelos créditos sub-prime surpreenderam autoridades governamentais, acadêmicos e profissionais do mercado. Não poucos perceberam a situação de risco que as principais economias do globo estavam correndo, em razão dos excessos dos mercados financeiros". Conclui o autor: "mas, para a maioria, a hipótese de uma catástrofe financeira era tida como improvável. Confiou-se muito na estrutura regulatória e de supervisão financeira e, principalmente, na capacidade de auto-regulação dos mercados" (2010, p.64).

Com isso, cria-se uma rede transgovernamental, composta por diferentes reguladores, que encontraram neste mecanismo a forma de acompanhar o ritmo acelerado de internacionalização dos agentes econômicos. Essa estrutura é estabelecida em laços de interesse comum, orientação profissional e amizade pessoal (KEOHANE e NYE, 1974, p.46). As redes consistem em um fórum para que os reguladores discutam os temas ligados à sua atividade e possam aprimorá-la, deixando de lado a atuação isolada e focada unicamente no âmbito interno.

Cumpre referir que a cooperação regulatória econômica, sob os auspícios do transgovernamentalismo tende a ser mais técnica, pois conduzida por órgãos especializados na matéria, em contraponto do modelo meramente diplomático e centralizador, que politizava a questão e deixava vulnerável à negativa de Estados protetores de seus próprios interesses.

Sobre a cooperação transgovernamental regulatória, Slaughter afirma que "são um importante mecanismo de governança global". Para a autora, "redes de oficiais governamentais engajam-se no mesmo empreendimento e ao encontrarem problemas similares no contexto doméstico podem trabalhar uns com os outros para remover obstáculos impostos pelas diferenças nacionais". Conclui, entendendo que existe uma troca de "informações sobre soluções promissoras" e o desenvolvimento de "abordagens comuns de problemas regulatórios" (2000, p.521-525).

\section{A IMPORTÂNCIA DOS "MEMORANDOS DE ENTENDI- MENTO"}

No direito internacional clássico, a principal fonte de direito é o tratado internacional. Observa-se que é uma norma típica do modelo tradicional e centralizador das relações internacionais, conforme mencionado no capítulo anterior. 
Três características devem ser mencionadas sobre os tratados internacionais. Primeiro, é um instrumento negociado por órgãos de cúpula da diplomacia estatal (chefe do executivo ou corpo diplomático).

Segundo, a posição de poder que estes agentes de Estado ocupam faz com que os interesses políticos nas negociações sejam predominantes. Nesse sentido, os assuntos essencialmente de ordem técnica, como aqueles envolvendo cooperação financeira, correm o risco de serem suplantados por estratégias políticas.

Terceiro, trata-se de instrumento de caráter formal, com exigências para adquirir validade e eficácia como norma jurídica. A principal delas é o procedimento conhecido como "internalização" ou "ratificação" do tratado internacional. Após ser assinado pelo representante estatal, é necessário que o ato seja referendado pelo poder legislativo pátrio, com o objetivo de ser convertido em norma interna e ter validade no território nacional. A negativa da aprovação por parte do legislativo implica a não adoção do instrumento jurídico internacional. No caso brasileiro, a burocracia do procedimento gera discrepâncias inacreditáveis: por exemplo, o Brasil demorou 40 anos para ratificar um dos documentos de maior relevância para o direito internacional, a Convenção de Viena de 1969 sobre o direito dos tratados.

Com o transgovernamentalismo, há uma redefinição das normas jurídicas internacionais, que adquirem novos contornos. Nesse cenário, destacam-se os chamados "memorandos de entendimento" (memorandum of understanding), de natureza diversa dos tratados internacionais e com características próprias.

Primeiro, são instrumentos jurídicos firmados diretamente com as subunidades estatais (no caso, agentes reguladores) sem qualquer participação ou intervenção dos órgãos centralizados de diplomacia. Como resultado, ao invés da negociação ser conduzida por setores que exercem uma diplomacia generalista (tratam de todos os assuntos da ordem internacional, como um Ministério das Relações Exteriores) serão os órgãos técnicos (uma entidade reguladora como a CVM) que estabelecerão conexões com suas contrapartes em outros países. Criados pelos detentores da experiência profissional e entendedores dos problemas de sua área, os memorandos de entendimento posam como uma excelente oportunidade para estabelecerem diretamente a cooperação, fixando pontos de contato.

Segundo, como se trata de um instrumento técnico, que tem como objetivo específico de firmar a cooperação entre os países de modo a promover o 
benefício mútuo, as questões de fundo meramente político acabam ficando em segundo plano.

Terceiro, é um documento despido de formalidade. Nesse sentido, é capaz de estabelecer procedimentos comuns para os reguladores e fixar alguns parâmetros para a cooperação, sem, contudo, apresentar a rigidez de um tratado internacional.

Em princípio, inexistem mecanismos sancionatórios para o descumprimento de um memorando de entendimento, além do tradicional princípio da reciprocidade: o descumprimento por uma parte acarreta a liberação da outra. Tal situação faz com que as subunidades estatais adotem os acordos de cooperação sem se preocuparem com possíveis sanções da comunidade internacional em caso de descumprimento. De modo geral, isso acaba sendo benéfico para a multiplicação de acordos, já que os benefícios para as ambas as partes são evidentes.

Outro ponto importante é a ausência de submissão ao escrutínio do poder legislativo. Os memorandos de entendimento valem como norma jurídica desde a sua criação. A ausência dessa formalidade também permite que a modificação do memorando seja feita de maneira rápida, sem o desgaste típico do tratado internacional.

Por tudo apresentado, conclui-se que os memorandos de entendimento constituem-se em documentos ideais para a cooperação: são, aparentemente, mais céleres, flexíveis e técnicos que os tratados internacionais.

A CVM vem aumentando sensivelmente o número destes acordos, pois o crescimento de transações transfronteiriças envolvendo valores mobiliários provoca uma crescente necessidade de aumentar os laços com autoridades equivalentes. O objetivo é garantir o nível adequado de proteção aos investidores e preservar a integridade do mercado. Esses acordos possibilitam a troca de informações públicas, como dados sobre a atuação de empresas e o intercâmbio de material sigiloso para fins investigativos.

Esta nova realidade na interação internacional entre Estados encontra respaldo na legislação aplicável à CVM. A Lei Complementar n ${ }^{\circ} 105 / 01$, em seu artigo $2^{\circ}, \S 4^{\circ}$, estabelece a possibilidade de a Comissão firmar convênios com entidades fiscalizadoras de outros países com o objetivo de fiscalizar empresas brasileiras e estrangeiras, bem como estabelecer a cooperação mútua e o intercâmbio de informações para investigação de atividades.

Da mesma forma, a Lei $n^{\circ} 10.303 / 01$, alterando a Lei ${ }^{\circ} 6.385 / 76$ (que disciplina a atividade da CVM), estabeleceu, no artigo 10, a possibilidade de celebração de convênios com órgãos similares de outros países. 
Por fim, o Regimento Interno da CVM (Portaria do Ministério da Fazenda $n^{\circ} 327 / 77$ ), em seu artigo 10, regulamenta o estabelecimento de relacionamentos com quaisquer entidades no exterior visando à troca de experiências e de informações.

Hoje, são quase 30 acordos firmados pela Comissão com diferentes reguladores de diversos países. Cada memorando possuiu escopo e amplitude determinados pela negociação entre os reguladores, fazendo com que tenham características próprias, embora sejam dotados de uma estrutura similar.

Em sua estrutura básica estabelecem a forma de trocas de informações e solicitações de assistência; o uso permitido das informações e questões de confidencialidade; o compartilhamento de custos de investigação ou assistência; a vigência do acordo e a indicação de pessoas de contato. Sobre esse último ponto, cumpre referir que ao final do memorando há um anexo contendo uma lista de pessoas de contato, informando seus telefones e endereço eletrônico, para que lhes sejam dirigidos os pedidos de assistência. Tal situação demonstra o caráter informal da cooperação transgovernamental.

Cumpre salientar que os pedidos de assistência são sempre limitados pelas questões de segurança e interesse nacional, geralmente constando no corpo do memorando ressalva expressa neste sentido. Sendo assim, há sempre a possibilidade de recusa do pedido de assistência, muito embora não seja esta a real intenção dessas redes.

Para demonstrar o funcionamento e as diferenças destes acordos de cooperação, foram selecionados três deles para análise um pouco mais detalhada.

Em 21 de junho de 1996, a CVM firmou junto à autoridade reguladora do mercado de capitais do Chile, a Superintendencia de Valores y Seguros (SVS), o memorando de entendimento que tem como finalidade o treinamento de pessoal e assessoria relativa ao desenvolvimento de sistemas para fomentar os mercados de capitais. Este acordo prevê assistências mútuas para consultas periódicas sobre práticas operacionais, evolução de sistemas para fiscalização do mercado e aplicação das leis e regulamentos.

Por sua vez, o memorando elaborado junto à Securities and Exchange Comission (SEC), órgão regulador do mercado de capitais dos Estados Unidos, firmado em $1^{\circ}$ de junho de 1988, é mais amplo, possibilitando maior interação entre os reguladores. Encontram-se previstos a completa assistência mútua na regulação do mercado; a fiscalização e o exame dos investimentos; a assistência para o fornecimento de informações constantes dos registros da autoridade requerida; bem como a obtenção de documentos e declarações de pessoas. 
O último dos memorandos selecionados para análise no presente artigo é o recentemente firmado junto à Autoridade Monetária das Ilhas Cayman (CIMA). Dito acordo foi assinado em 24 de fevereiro de 2009, após aproximadamente dois anos de negociação entre as partes. A escolha deste acordo deu-se em virtude da consideração da contraparte como um paraíso fiscal pela legislação brasileira, face ao sigilo conferido às informações societárias das companhias constituídas sob suas leis (art. $24, \S 4^{\circ}$ da Lei $n^{\circ}$ 9.430/96).

O acordo prevê o fornecimento de informações sobre registro de transações de ações, incluindo dados de todos os fundos e ativos transferidos, de modo a identificar o beneficiário final e o controlador para cada operação, o proprietário da conta, o valor adquirido ou vendido, a data da transação, o preço da transação e os intermediários (quer seja instituição financeira, quer seja pessoa física).

Entende-se que a negociação deste acordo ocorreu em virtude da identificação pelo regulador nacional da necessidade de minimizar o impacto decorrente do sigilo conferido às empresas constituídas sob o direito das Ilhas Cayman e que atuam no mercado brasileiro. $\mathrm{O}$ foco dos pedidos de assistência consiste justamente em formas de romper com o sigilo em determinadas hipóteses, evidenciando a efetividade deste mecanismo dentro do novo cenário internacional.

Na ausência deste mecanismo restaria apenas a possibilidade de negociação pelos chefes de cada Estado para a elaboração de tratado internacional, percorrendo todo seu tortuoso caminho. Tendo a negociação do memorando perdurado por cerca de dois anos, deve-se indagar: quanto tempo tomaria a elaboração de um tratado? Ou, ainda, seria viável esta troca de informações dentro de um cenário de maior formalismo e rigidez?

Como visto, os memorandos de entendimento se revestem de grande informalidade e consistem em mecanismos céleres para a troca de informações, de experiências e obtenção de documentos, até mesmo com caráter investigativo, entre os reguladores de diferentes países. Entende-se que consistem em excelente mecanismo para operacionalização da atividade regulatória em um mundo de interações transnacionais.

A atuação dos reguladores neste formato deu origem a outras formas mais sofisticadas e estruturadas para a interação entre eles, inclusive impulsionando o surgimento de organismos internacionais que congregam grande 
quantidade de reguladores, no intuito de facilitar esta interação e até mesmo de ampliá-la.

\section{O NOVO PAPEL DAS ORGANIZAÇÕES INTERNACIONAIS}

O esquema de cooperação transgovernamental também é responsável pelo estabelecimento de um novo papel às organizações internacionais. Elas desempenham a importante função de auxiliar a aproximação dos agentes governamentais, por meio da promoção de conferências e encontros, criandose um fórum internacional de discussão sobre assuntos regulatórios. Sob esse aspecto, a institucionalização da cooperação é benéfica, pois permite o incremento das redes de cooperação da seguinte forma: as organizações internacionais provêem, por meio de suas reuniões, um local para que o contato pessoal seja feito; definem uma agenda de temas e problemas a serem debatidos pelos participantes; e por fim, conferem uma aura de legitimidade à cooperação (KEOHANE e NYE, 1974, p.51).

Outro aspecto de extrema relevância da atuação dessas instituições internacionais reside na elaboração de documentos que servirão de base para a construção de um arcabouço normativo sobre a cooperação jurídica transnacional. Contudo, essa produção jurídica não é revestida da forma tradicional, que envolveria o desenvolvimento de tratados internacionais e atos normativos vinculativos de órgãos internacionais. Observa-se a prevalência de soft law, normas jurídicas que orientam condutas sem serem de caráter imperativo ou coercitivo. Como exemplos, têm-se as recomendações, leis modelos e documentos dispondo sobre melhores práticas no setor ou princípios orientadores. Objetivo é estabelecer o diálogo entre os diferentes atores transnacionais, sem impor a vontade utópica de uma autoridade supranacional, desvinculada das necessidades práticas.

Na regulação do mercado financeiro essas organizações estão divididas por setores. O mercado bancário é regulado pelo Basel Committee on Banking Regulation and Supervisory Practices, conhecido no Brasil como Comitê da Basiléia. Instituído em 1974, seu objetivo é prover maior solidez e estabilidade para o sistema bancário por meio da uniformização dos princípios gerais de supervisão. Seu estatuto prevê quatro encontros anuais entre seus membros para discussão de temas afeitos ao mercado bancário e sua supervisão.

$\mathrm{Na}$ área de seguros, existe a International Association of Insurance Supervisors (IAIS), que foi criada em 1994 e congrega entre seus membros 
os supervisores do mercado securitário de 190 países. Seu objetivo é fornecer, através de princípios standards e pareceres de orientação, treinamento e suporte em questões relacionadas à supervisão securitária e organizar seminários e encontros entre os reguladores de seguros. Seu funcionamento ocorre por meio de comitês (executivo, técnico e de implementação).

No que diz respeito à regulação do mercado de capitais, o fórum internacional é a International Organization of Securities Commissions (IOSCO), também conhecida como Organização Internacional das Comissões de Valores (OICV). Foi criada em 1983, tendo inicialmente surgido como um organismo interamericano. A CVM foi um dos órgãos nacionais fundadores. Atualmente, congrega cerca de 130 membros de 80 países e é considerada como o principal fórum internacional para as autoridades reguladoras dos mercados de valores e de futuros.

A IOSCO possui três grandes objetivos básicos: proteger investidores; assegurar mercados justos, eficientes e transparentes; e reduzir o risco sistêmico. Para isso, promove, por meio da cooperação, altos padrões de regulação, adequados à manutenção de mercados dotados de segurança e estabilidade. Além disso, compromete-se em ajudar no intercâmbio de informações e difusão de experiências necessárias para o desenvolvimento de mercados domésticos. $\mathrm{Na}$ área da harmonização, esforça-se em estabelecer padrões internacionais de auditoria e a implementar um sistema eficaz de supervisão das transações internacionais no mercado de capitais. Por fim, no que diz respeito ao setor de correição, visa proporcionar assistência recíproca nas investigações, com a finalidade de garantir a rigorosa aplicação das leis e punição de seus infratores.

Suas normas jurídicas manifestam-se na emissão de recomendações, princípios entendidos como melhores práticas regulatórias, para que seus membros as implementem no âmbito interno. Isto pode ser realizado pelos diversos comitês técnicos, mediante a elaboração de relatórios de implementação dos princípios e da emissão de documentos para discussão entre seus membros para o aprimoramento das técnicas regulatórias.

A divulgação de princípios é dirigida a todos os agentes envolvidos com operações no mercado de capitais, incluindo emissores, gestores de fundo, intermediários e integrantes do mercado secundário.

Com a emissão de recomendações de melhores práticas pela organização internacional, aumenta-se a possibilidade de comparabilidade entre os sistemas regulatórios de cada país, de modo a permitir a aferição do nível de segurança jurídica. Há também o estabelecimento de um padrão regulatório mínimo a ser 
adotado com o objetivo de diminuir o descompasso entre os direitos e instituições nacionais.

Tendo em vista a grande interdependência entre os mercados, tais esforços têm conseguido a adesão de um número cada vez maior de nações. A vinculação é facultativa pelas comissões de valores mobiliários nacionais, embora se notem fortes incentivos à internalização de tais recomendações, como instrumento de política macroeconômica benéfico ao ingresso de capitais nos mercados nacionais.

A título de melhor ilustração do tema aqui tratado, faz-se referência à alteração do padrão contábil recentemente operada no direito brasileiro, em um verdadeiro movimento de convergência internacional. A IOSCO, em seu princípio de $\mathrm{n}^{\mathrm{o}} 16$, dirigido aos agentes emissores, expressamente recomenda a adoção de padrões contábeis e de auditoria de elevada e internacionalmente aceitável qualidade.

O padrão internacionalmente aceito é confeccionado pela International Accounting Standards Board (IASB), que emite as chamadas International Financial Reporting Standards (IFRS). Estas consistem em padronização dos procedimentos contábeis para a divulgação de resultados financeiros de companhias.

A utilização deste formato permite a padronização mundial na divulgação, conferindo aos destinatários da informação melhores condições de comparabilidade dos resultados de empresas sediadas em diferentes países. A título de exemplo, cumpre referir que a legislação pátria previa a utilização de padrão próprio, denominado BR GAAP, enquanto a americana impõe divulgação de informações pelo padrão denominado United States' Generally Accepted Accounting Principles (US GAAP). A criação do IFRS elimina as diferenças, estabelecendo um "idioma" internacional para divulgação e análise das informações financeiras.

Dada a necessidade de convergência internacional, o legislador pátrio, através da Lei $n^{0} 11.638 / 07$, alterou a legislação sobre o tema, impondo a adoção gradativa do padrão internacional às companhias brasileiras. Foi estabelecido um cronograma para implementação em etapas do novo formato, iniciado em 2008 e com prazo final para 2010. Ainda que já adotado o novo formato, as companhias e a classe profissional (auditores e contadores) vêm travando acirradas discussões acerca do tema, principalmente em virtude de dúvidas e sugestões de aprimoramento. 
A convergência contábil ilustra muito bem o resultado da atuação dos organismos internacionais, uma vez que das discussões neles estabelecidas e das recomendações por eles expedidas advêm consideráveis alterações no âmbito interno, corroborando, assim, a efetividade decorrente do funcionamento destes órgãos.

Os próprios organismos internacionais em matéria financeira também produzem comunicação entre si. O entendimento é que o mercado financeiro, apesar de sua segmentação em quatro grandes ramos, não pode ser tratado de maneira estanque, porque há significativa interação entre os diferentes agentes. Sendo assim, os organismos internacionais de diferentes segmentos passaram a compartilhar informações e experiências no campo regulatório.

Esta interação deu azo à criação de um novo fórum internacional. Tratase do Financial Stability Forum, fundado em 1999 pelos membros do G8, por diversos organismos internacionais ligados ao mercado financeiro e pelos presidentes de bancos centrais de diversos países. Sua finalidade é estabelecer um local justamente para troca de experiências e de informações entre diferentes segmentos, possibilitando, assim, um panorama mais amplo e completo dos mecanismos regulatórios e principalmente da economia mundial. O fórum sofreu alteração em sua estrutura em 2009 e passou a adotar a denominação Financial Stability Board, que prevê a realização de no mínimo uma reunião anual entre seus membros para propiciar a discussão de temas relevantes.

No âmbito do Mercado Comum do Sul (MERCOSUL), a CVM integra a Comissão de Mercado de Capitais do subgrupo de trabalho 4, coordenado pelo Banco Central do Brasil, dentro do Grupo Mercado Comum (GMC). Recentemente, a CVM, por meio da Deliberação $n^{\circ} 659 / 11$, aprovou a incorporação da decisão 31/10 do Conselho Mercado Comum do MERCOSUL, referente à regulamentação mínima do mercado de valores mobiliários sobre a elaboração das demonstrações financeiras.

De acordo com a deliberação, a partir de 2012, as companhias que desejarem negociar seus valores mobiliários no espaço do MERCOSUL deverão apresentar suas demonstrações financeiras de acordo com o IASB. Esta decisão parte do princípio de que o processo de integração dos mercados de valores mobiliários do MERCOSUL requer normas padronizadas de divulgação de informação por parte dos emissores, tornando-as convergentes com as práticas contábeis internacionais. 


\section{CONCLUSÃO}

A velocidade e a intensidade da circulação de capital e das crises financeiras impõem a adequação dos órgãos regulatórios a uma nova realidade. Para tanto, são elaboradas novas formas normativas e arranjos institucionais que permitem o estabelecimento de canais mais céleres e flexíveis, capazes de conferir maior proximidade do regulador aos agentes do mercado. Nesse sentido, faz-se necessário o desenvolvimento da regulação financeira sob a forma de redes de cooperação.

Cumpre referir que o risco financeiro não pode ser visto isoladamente, mas de maneira sistêmica e global. Sendo assim, os reguladores devem atuar de forma transnacional, sob pena de sua atividade resultar em ineficácia até mesmo no cenário interno, uma vez que as regras estabelecidas nacionalmente não são mais suficientes para alcançar a efetividade no mercado financeiro. Os mecanismos de cooperação internacional devem ser estimulados e aprimorados a fim de que se crie uma nova arquitetura mundial de regulação, visando, principalmente, à eficiência da atividade regulatória.

As redes de cooperação internacional preenchem uma função importante, pois as tradicionais formas de atuação do Estado no cenário internacional jamais atingiriam a extensão e a qualidade do trabalho por elas desempenhado. As atividades desenvolvidas pelos organismos internacionais igualmente revelamse eficazes, pois com o estabelecimento de standards, emerge um padrão regulatório mínimo capaz de conferir maior segurança jurídica aos investidores.

A atuação das redes talvez não evite o acontecimento de novas crises financeiras, no entanto é notável o aprimoramento dos mecanismos e dos instrumentos regulatórios que advêm de sua atividade, o que certamente contribuirá para a diminuição do impacto das novas crises na economia mundial.

\section{REFERÊNCIAS}

ARAGÃO, Alexandre Santos de. Agências reguladoras e a evolução do direito administrativo econômico. Rio de Janeiro: Forense, 2003.

ARNAUD. André-Jean. O Direito entre Modernidade e globalização: lições de filosofia do direito e do Estado. Rio de Janeiro: Renovar, 1999. 
BANK FOR INTERNATIONAL SETTLEMENTS. Basel Committee on Banking Supervision. Disponível em: $<$ http://www.bis.org/bcbs $>$. Acesso em: 4 jul. 2011.

BINENBOJM, Gustavo. Uma teoria do Direito Administrativo: direitos fundamentais, democracia e constitucionalização. 2. ed. Rio de Janeiro: Renovar, 2007.

BRUNER, Robert F.; CARR, Sean D. The panic of 1907. Lessons learned from the market's perfect storm. New Jersey: John Wiley \& Sons, Inc, 2007.

COMISSÃO SOBRE GOVERNANÇA GLOBAL. Nossa Comunidade Global. Rio de Janeiro: Fundação Getúlio Vargas, 1996.

FSB. Financial Stability Forum. Disponível em: $<$ http:// www.financialstability board.org/publications/r_0904c.pdf $>$. Acesso em: 9 jul. 2011.

IAIS. International Association of Insurance Supervisors. Disponível em: $<$ http://www.iaisweb.org $>$. Acesso em: 10 jul. 2011.

IANNI, Octávio. Teorias da Globalização. 12 ed. Rio de Janeiro: Civilização Brasileira, 2004.

KEOHANE, Robert O; NYE JR., Joseph S. Transgovernmental Relations and International Organizations. World Politics, Maryland, v.27, n.1, out.1974, p.39-62, 1974.

. Transnational Relations and World Politics: an Introduction.

International Organization, Cambridge, v.25, n.3, p.329-349, 1971.

LOYOLA, Gustavo. Risco e regulação: porque o Brasil enfrentou bem a crise e como ela afetou a economia mundial. Rio de Janeiro: Elsevier, 2010.

OICV-IOSCO. International Organization of Securities Commissions. Disponível em: <http://www.iosco.org>. Acesso em: 4 jul. 2011.

SADDI, Jairo. Temas de regulação financeira. São Paulo: Quartier Latin, 2010. 
SLAUGHTER, Anne-Marie. A new world order. Princeton: Princeton University Press, 2004.

. Agencies on the loose? Holding government networks accountable. In: BERMANN, George A.; HERDEGEN, Matthias; LINDSETH, Peter L. Transatlantic regulatory cooperation: legal problems and political prospects. Oxford University Press: Oxford, 2000. p.521-525.

. The real new world order. Foreign Affairs, New York, v.76, n.5, p.183-197, sep./oct. 1997.

YAZBEK, Otávio. Regulação do mercado financeiro e de capitais. Rio de Janeiro: Elsevier, 2009.

Recebido em: 2011-10-14 Aprovado para publicação em: 2012-08-06

Como citar: FERREIRA, Luciano Vaz; LUCIETTO, Marcelo Leão. A cooperação transgovernamental financeira na regulação dos mercados de capitais. Scientia Iuris, Londrina, v.16, n.1, p.161-178, jul.2012. DOI: 10.5433/2178-8189.2012v16n1p161. 